\title{
„Pădurile din Europa sunt în pericol - noi oferim soluțiī" - a 30-a aniversare Pro Silva, 11-14 Septembrie 2019, Radlje ob Dravi, Slovenia
}

\section{Introducere}

Conștienți de provocările contemporane și îngrijorați pentru viitorului pădurilor şi al silviculturii, un grup de 20 de silvicultori eminenți din 10 țări, s-au întâlnit acum 30 de ani, în Slovenia și au discutat despre o abordare integratoare, ,holistică”, a silviculturii, așa zisa „close-to-nature forestry”, un concept considerat mai mult filozofic. De remarcat este că printre ei se aflau profesori universitari de la unele din cele mai renumite universități, practicieni silvicultori cu mare experiență, proprietari de păduri dar şi o categorie foarte interesantă: silvicultori-proprietari de pădure. Această ultimă categorie a avut şi are un rol deosebit în dezvoltarea şi implementarea în practică a conceptului ,close-to-nature forestry”. Astfel, prin abordarea lor particulară aceștia implică o componentă economică obligatorie prin faptul că îsi asigură venitul din valorificarea resurselor pădurii dar și fac tot posibilul pentru a păstra potențialul resurselor forestiere pentru viitoarele generații ale familiei, prin practicarea unei gospodării durabile a resursei, bineînțeles în contextul respectării reglementărilor legale, inclusiv a mult discutatelor cerințele ecologice sau celor mai generale de mediu, care implicit le protejează proprietatea pe termen lung.

Așa s-a născut Pro Silva, ca o asociație care promovează o silvicultură bazată pe principii legate de natură și un management forestier în deplină concordanță cu natura, având as- tăzi peste 5400 de membri, experți silvici sau proprietari de pădure. Cu siguranță, Uniunea Europeană este locul unde acest concept își găsește mai repede nișa, mai ales în contextul extinderii recente a rețelei Natura 2000, iar România, ca țară cu una din cele mai pronunțate naturalități a pădurilor dintre țările UE, are un context favorabil aplicării acestui tip de silvicultură. Conceptele de bază din silvicultura tradițională din țara noastră sunt de mult timp pe aceiași linie cu o silvicultură aproape de natură, România fiind alături de Elveția, Slovenia și Germania, țările unde managementul forestier durabil, se aplică la peste jumătate din suprafața actuală a pădurilor. Aplicarea prea schematică și refuzul multor silvicultori de a acționa în spiritul acestor principii și ascunderea deciziilor proprii după prevederi prea generale sau generalizate, face ca de multe ori în practică sa se producă greșeli în ciuda unor evidențe de necontestat.

Atât aspectele economice cât și valențele ecologice ale silviculturii, sunt prea mult şi pe nedrept neglijate și societatea nu iartă aceste greșeli. Valorificarea superioară a resurselor se măsoară și se raportează de multe ori doar în $\mathrm{m}^{3}$ și pierderile sunt valoric imense și din această cauză. Serviciile aduse de pădure societății, așa zisele servicii ecosistemice, nu intră de obicei în calculele cotidiene ale administratorilor, din păcate. Din aceste motive, una din cele mai dorite și iubite profesii a ajuns cu probleme teribile de imagine. Orice arbore 
tăiat este o imagine negative, orice animal sălbatic recoltat prin împușcare stârnește compasiune și milă. Aerul curat, apa, toate beneficiile aduse de pădure sunt privite încă de societate ca un drept natural, fără să se tină cont de contextul actual când menținerea acestor beneficii într-un mediu natural tot mai antropizat generează costuri.

Pe lângă toate problemele deja tradiționale ale silviculturii, ne confruntăm astăzi cu efectele schimbărilor climatice care produc doborâturi de vânt și atacuri de insecte și boli, evenimente de o amploare nemaiîntâlnită și catastrofale pentru păduri.

\section{Care este în acest context viitorul silviculturiị?}

Pro Silva vine cu exemple din experiența proprie ce pot constitui soluții la provocările actuale ale silviculturii. În acest context s-a desfăşurat conferința -,,Pădurile din Europa sunt în pericol - noi oferim soluții" - a 30-a aniversare Pro Silva, desfãșurată în 12 Septembrie 2019, la Radlje, în Slovenia, urmată de excursii în teren și a adunare generală a asociației.

In deschiderea conferinței, Klaus Puetmann, Oregon State University, a prezentat lucrarea: Cercetări contemporane în domeniul silviculturii ecologice: ,De la designul problemei la diseminare" (Contemporary research in the field of ecological forestry: "From problem design to dissemination", https://www.prosilva.org/fileadmin/prosilva/2 Events/01 Annual Meetings/2019_Slovenia_Radlje/NEWS_Radlje/ Presentation_PUETTMANN_30years_ProSilva_12092019.pdf). În lucrarea a fost prezentată o retrospectivă a interesului global pentru silvicultura aproape de natură și s-a subliniat că cercetările recente arată cu nu toate componentele structurale și de compoziție ale pădurilor răspund similar tratamentelor silviculturale aplicate iar în final au fost prezentate modalităţi privind răspunsul silviculturii aproape de natură la nevoia de asigura o multitudine de servicii ecosistemice într-o varietate de situații în contextul de ecologic și social dat de schimbările globale actuale.

Peter Amman, de la Fachstelle Waldbau, Lyss, Elveția a prezentat lucrarea: „Integrarea practicienilor în cercetarea academică pentru progresul în silvicultura aproape de natură" (Integarting practitioners into academic research for improvement of close-to-nature forestry, https://www.prosilva.org/fileadmin/prosilva/2 Events/01 Annual Meetings/2019 Slovenia_Radlje/NEWS_Radlje/Presentation AMMANN_30years_ProSilva_12092019. pdf), în care a fost detaliat conceptul de raționalizare biologică, dezvoltat după 90 de ani de experiență în Elveția, dintre care 30 de ani de experiență proprie și în care s-a discutat conceptul de selecție individuală a arborilor în contextul de schimbări climatice rapide și integrarea acestuia cu silvicultura aproape de natură.

,30 de ani de Pro Silva Europa - realizări și provocări viitoare" (Thirty years of pro Silva Europe, achievements and challenges for the future, https://www.prosilva.org/fileadmin/prosilva/2_Events/01_Annual_Meetings/2019_Slovenia_Radlje/NEWS_Radlje/ Presentation_CARVALHO_30years_ProSilva_12092019.pdf), o sinteză a ce reprezintă Pro Silva după 30 de ani, făcută de Joao Carvalho - Pro Silva Portugalia și realizată pe baza unui chestionar transmis țărilor membre Pro Silva și interpretat de către Bill Mason - președintele Continuous Cover Forestry Group, Jurij Diaci - Pro Silva Slovenia și Sauli Valkoneneste - Luki Finlanda, arată că aproape o treime din pădurile Europei sunt administrate într-un sistem silvicultural ce asigură continuitatea pădurii și asociat cu tipul de silvicultura aproape de natură. Chiar dacă există astăzi o lipsa acută de informații despre acest subiect, este evident ca tipul acesta de silvicultură va crește probabil ca răspuns la cererea socială și la inițiativele politice actuale. Principalele provocări legate de extinderea acestui tip de silvicultură sunt legate și de o pregătire profesională adecvată a silvicultorilor în strânsă legătură cu provocările politice (cum ar fi și reducerea 
numărului de erbivore ungulate în majoritatea țărilor europene pentru a putea promova regenerarea naturală), culturale și de infrastructură actuale. $\mathrm{Cu}$ siguranță, este absolut necesar ca Pro Silva să promoveze activ cercetările în domeniu astfel ca silvicultura aproape de natură să se extindă.

Silvicultura din Slovenia, o țară acoperită în procent de peste $58 \%$ cu păduri (suprafaţa totală 1177244 ha dintre care 98762 păduri de protecție și 9518 rezervații forestiere), a fost prezentată de către Directorul Serviciului Forestier Sloven, Damian Orazem. In Slovenia, tăierile rase au fost interzise imediat după al doilea război mondial. Peste $77 \%$ din pădurile din Slovenia sunt în proprietate privată, sunt 413000 de proprietari cu o suprafață medie de 2-3 ha/proprietar. Fagul este principala specie în Slovenia, urmat de brădeto-făgete și păduri mixte de stejari și fag, cu o medie a masei lemnoase pe picior de $302 \mathrm{~m}^{3} /$ ha și o creștere medie de 7,48 $\mathrm{m}^{3} / \mathrm{ha}$. În 2018 , s-au recoltat în Slovenia $6000000 \mathrm{~m}^{3}$ (69\% din posibilitatea anuală), din care $70 \%$ au fost rășinoase recoltate în mare măsură din tăieri accidentale și de igienă ca urmare a doborâturilor de vânt și a atacurilor de insecte. O mare parte a lemnului din Slovenia este exportat. Peste 70\% din Pădurile Sloveniei sunt incluse în rețeaua Natura 2000. Serviciul Forestier Sloven (peste 700 de experți forestieri) este finanțat exclusiv de bugetul de Stat. Protecția pădurilor în Slovenia este asigurată ca serviciu public prin Serviciul Forestier Sloven și prin Institutul Forestier Sloven şi are ca principal obiect de activitate lupta împotriva gândacilor de scoarță și invaziile biologice în ecosistemele forestiere.

Începând cu 2016, valorificarea resurselor pădurilor din Slovenia a fost preluat de Compania Slovenă a Pădurilor de Stat prin 4 Direcții și 28 de secții care valorifică resursa a 236000 de ha păduri (21\% din suprafața totală a pădurilor din Slovenia). Pentru valorificarea resursei lemnoase se lucrează aici atât cu angajaţi proprii (20\%) cât și cu firme pe bază de contract atribuit prin licitații. Venituri companiei de aproximativ 77 milioane euro/an ge230 nerează 14,6 milioane de euro pentru Fondul Pădurilor și 14 milioane euro profit.

Vânătoarea și managementul cinegetic în Slovenia, se desfășoară prin Asociația Vânătorilor din Slovenia și 408 fonduri de vânătoare cu o suprafață medie de 4500 ha administrate de 416 familii de vânători reunite în 18 asociații regionale de vânătoare și având un număr de 22000 de vânători.

In teren s-a vizitat pădurea Pahernik, constituită în forma juridică de astăzi în urma unei donații din partea fostului proprietar, cu acelaşi nume, un precursor al silviculturii aproape de natură şi administrată din 2010 de fundația $\mathrm{Pa}$ hernik, care are următoarele caracteristici: 453 $\mathrm{m} 3 /$ ha, o creștere de $10,8 \mathrm{~m} 3 /$ ha, o posibilitate de $8.0 \mathrm{~m} 3 /$ ha, $82 \%$ conifere $(67 \%$ molid, $12 \%$ brad, $16 \%$ fag). Producția este orientată pe obținerea de lemn de calitate, iar profitul anual este de 190 euro/ha. Efortul anual investit în regenerarea pădurii, rărituri și protecția pădurii este de 1oră/ha. După îndesirea rețelei de drumuri forestiere s-a putut trece la o Recoltarea lemnului se face cu moto-manual cu fierăstrăul iar densitatea drumurilor forestiere este de $36,8 \mathrm{~m} / \mathrm{ha}$. In cadrul proiectului INTEGRATE+, în scop educativ, a fost inclus un marteloscop in pădurea Pahernik și astfel se fac simulări privind rezultatele oricărei intervenții făcute în urma unei atente observări a contextului şi luări de decizii care să fie rezultatul obținut prin aplicarea principiilor teoretice cunoscute ale silviculturii într-un context particular, cu toți factorii de influență locali luați în considerare. De asemenea, ca un exemplu de gospodărire durabilă de-a lungul secolelor, s-a vizitat ferma Sgerm, din regiunea Pohorje, formată din 52 ha de pădure și 11,5 hectare de pășune. Această fermă folosește selecția individuală a arborilor, iar pentru exploatarea lemnului, doborârea manuală și trasul cu atelaje cu cai, utilizarea lemnului pentru nevoi proprii și vânzarea lemnului rămas, în special a celui de lucru, valoros, realizând astfel o gospodărire durabilă de-a lungul timpului. Veniturile obținute astfel, împreună cu cele din creșterea animalelor asigură cu continuitate un nivel 
de viață decent pentru familia de proprietari. Conform măsurătorilor făcute și reconfirmate recent, aici se găsește și cel mai înalt arbore nativ din Europa, un molid de 62,124 m înălțime, $124 \mathrm{~cm}$ diametru și cu o vârstă de 270 de ani. Vizitele în teren au excelat în prezentarea unor aspecte deosebit de interesante ale tradițiilor silviculturale din Slovenia: cu aspecte privind administrația pădurilor de stat și conversia graduală și îndelungată a monoculturilor de molid din Bricka, Mislinia, Direcția Silvică Regională Gradec și prezentarea pădurilor naturale remanente la ferma Jauh (3000 ha) în contextual tăierilor rase practicate în prima jumătate a secolului trecut, prezentate de ing. Mirko Cehner, aspecte privind bazele silviculturale ale plantării fagului sub monoculturile de molid prezentate de Matjas Cater de la Institutul Forestier Sloven. Integrarea cu succes a conservării naturii în sistemul de amenajare al pădurilor din Slovenia în cadrul a numeroase proiecte (NATREG, WETMAN, ALPIA, ...), având în vedere principalele prevederi legislative în vigoare din domeniul protecției naturii și silviculturii, a fost prezentată pentru zona Pohorje de Jurij Gulic. Succesiunea naturală în păşunile abandonate și plantarea sub masiv a fagului și Silvicultura de tip free-style în proprietăţile de mărime medie a fost prezentată de ing. Samo Susek de la Serviciul Forestier Sloven şi de Alojzij Klancnik, pensionar silvic. Metoda controlului în Slovenia, utilizare și aplicabilitate în scop de cercetare, a fost prezentată de Matija Klopcic de la Universitatea din Ljubliana și de Ales Poljanec de la Serviciul Forestier Sloven. Managementul forestier selectiv în zona Maribor și aplicarea metodei controlului în Lehen au fost prezentate de către Ljubo Cencic de la Serviciul Forestier Sloven ca argumente în favoarea unui management forestier cât mai aproape de natură. Pădurea urbană Celje a fost prezentată de către Robert Hostnik, de la Serviciul Forestier Sloven, ca o poveste de succes în Slovenia, unde membrii societăți manifestă o sensibilitate deosebită pentru natură şi pădure.

In ansamblu, reuniunea de la Radlje, Slo- venia a fost un eveniment remarcabil care va rămâne în memoria participanților și nu numai prin cel puțin două aspecte: a fost pentru prima dată când Pro Silva adoptă o declarație politică și înființarea Muzeului Silviculturii Aproape de Natură la Radlje ob Dravi.

\section{Declarația Pro Silva de la Radlje ob Dravi, -"păduri- le din Europa sunt în pericol - oferim soluții".}

Gândacii de scoarță și seceta ucid mii de hectare de păduri în Republica Cehă, Austria de Nord, Germania, Franța, Belgia etc... Nu numai molidul este pe moarte, ci si bradul, pinul silvestru, frasinul și alte specii de arbori. Un rezumat al rapoartelor din partea țărilor membre ale Pro Silva a arătat că o serie de ani de secetă, unde precipitațiile anuale ajung la doar $50-60 \%$ din mediile pe termen lung conduc la efecte dramatice asupra pădurilor europene. În special în partea de nord a Europei Centrale, au explodat recent infestările cu gândacii de scoarță ai molidului (de exemplu, Boemia Moravia, Alsacia, Germania), iar frecvența incendiilor forestiere este fără precedent (de exemplu, pădurile de pini din Brandenburg).

Chiar și pădurile naturale seculare de fag sănătoase pana acum sunt afectate, în special pe soluri mai bogate si in condiții de umezeala ridicata (ex. Spessart, Alsacia). De asemenea, plantaţiile de stejar tineri nu pot rezista schimbărilor rapide ale condițiilor de mediu.

Ca urmare, piața lemnului s-a prăbușit, chiar și exporturile către China nu pot face întreprinderile forestiere profitabile și mulți mici proprietari de păduri mici pur și simplu au renunțat sa mai comercializeze lemn.

In mai multe state europene sunt dezvoltate astăzi programe forestiere de salvare a pădurilor. În spatele acestora există un lobby puternic al grupurilor forestiere conservatoare care doresc să continue cu practicile lor tradiționale și să îşi mențină status quo-ul. Ei doresc sa promoveze varietăți genetice de molid, care pot supraviețui şi să prospera în condiții climatice mai uscate. Dar ei luptă împotriva neo- 
bositelor forțe determinate de schimbările climatice . O selecție bazată pe efecte epigenetice oferă o modalitate alternativă mai rapida decât ameliorarea tradițională bazata pe reproducere care este lentă şi poate dura decenii.

Procesele naturale și regenerarea oferă maximul din punctul de vedere al schimbului genetic și al adaptării evoluţioniste. In acest sens, natura și-a găsit drumul de-a lungul anilor, dar in silvicultură avem nevoie astăzi de o schimbare majoră de paradigmă. Cele mai recente evidente științifice (Rupert Seidl, Thomas Vrska) care arată că pădurile de amestec, bine structurate, cu procese dinamice care se bazează pe regenerarea naturală ajută la stabilizarea pădurii trebuie să fie luate în considerare de practicile forestiere. $\mathrm{Cu}$ toate acestea, ar trebui totodată să fim deschiși la utilizarea diferitelor proveniențe de specii „,noi” de arbori, neignigeni, care trebuie să fie ghidate şi sa beneficieze de o ,migrație asistată” în pădure. De asemenea, nu este posibil să reîmpădurim toate zonele perturbate, deoarece nu există suficiente resurse in pepiniere şi nici personalul calificat necesar! Trebuie însă să combinăm plantarea unui număr mic de puieți din speciile de arbori țintă (500/ha) și totodată să lăsam spaţiu pentru succesiuni naturale intercalate, pentru crearea de păduri mixte cu structură neregulată și sol sănătos. Presiunea pășunatului selectiv exercitat de ungulate şi atât de răspândit in Europa de astăzi (cerb, cerb lopătar, căprior, etc.) poate stopa regenerarea naturală şi de multe ori duce la extincția unor specii de arbori importante cum sunt bradul sau speciile de stejar, specii care nu se pot regenera fără împrejmuiri sau alte tipuri de protecție artificială. Directivele din domeniul cinegetic trebuie să fie schimbate pentru putea asigura controlul populaţiilor de ungulate și pentru a preveni acesta invizibilă agresiune, letala pentru păduri.

In situația de astăzi când chiar și pădurile naturale sau semi-naturale, precum și pădurile din zonele protejate complet sunt afectate de fenomene de uscare, solicitarea ONG-urilor şi comunităţii de specialiști in protecţia naturii pentru a crește suprafața de păduri aflate in re232 gim de ,protecție strictă” este discutabilă. De asemenea, conceptul Natura 2000 trebuie să se schimbe urgent, din cauza efectelor schimbărilor climatice și de redefinire a obiectivelor de protecție. Pădurile noastre au nevoie de management modern orientat spre natură, care ajută cele mai bine adaptate specii de arbori şi arbori individuali să se dezvolte. Cele mai importante probleme în viitor vor fi de a marca arborii pentru tăierile selective și de a ajuta rărirea arboretelor tinere.

Avem nevoie de mai mulţi silvicultori calificaţi în pădure, nu în birouri, și de muncitori forestieri calificați!

Importanța imensă a serviciilor ecosistemice furnizate de pădurile europene, în combinație cu o utilizare economică durabilă a resurselor de lemn, necesită o abordare integratoare a gestionării pădurilor, așa cum este promovată de Pro Silva. Managementul forestier este singura activitate economică care poate produce lemn valoros într-un proces de stocare a carbonului, pe de o parte in lemn mort și humus în păduri, iar pe de alta parte in produsele din lemn pentru construcții și alte utilizări.

Consumul de $\mathrm{CO} 2$ va fi unul din cele mai importante elemente economice in viitor, la fel ca şi substituirea in diverse moduri a materialelor obişnuite din combustibili fosili (bioeconomie).

La aniversarea a 30 de ani Pro Silva face apel la exercitarea unui tip de management aproape de natură activ şi durabil al pădurilor. Toate statele europene sunt încurajate să elaboreze cadrul juridic și financiar pentru punerea în aplicare a unui astfel de tip de management forestier aproape de natură atât în pădurile publice cat și în pădurile private.

$\mathrm{Cu}$ toate acestea, acest lucru poate fi realizat numai cu condiția ca guvernele sa schimbe practicile actuale de management cinegetic și directivele de vânătoare pentru a permite pădurilor să crească! - Într-un sistem fiscal bazat pe mecanisme legate de stocarea carbonului, silvicultura aproape de natura trebuie să obțină avantaje!

Pro Silva este formată din silvicultori prac- 
ticanți și oameni de știință, o rețea impresionantă, cu un set de principii fundamentate şi dezvoltate de-a lungul a peste 30 de ani. Numeroasele declarații existente pe site-ul nostru www.prosilva.org sunt linii directoare pentru o mai bună gestionare a pădurilor viitorului. În plus, oferim doritorilor o rețea de "păduri exemplu" în toată Europa pentru a le vizita și a le studia evoluțiile recente şi in plus, oferim cele mai bune strategii pentru conservarea pădurilor!

Prin tema conferinței internaţionale de la Radlje cu titlul „Păduri pentru viitor - de la știința la oameni", Pro Silva vrea să dea un nou impuls pentru o mai bună punere în aplicare a rezultatelor științifice în practică, dar și în a facilita o mai bună colaborare și integrare a contribuțiilor practicienilor cu știința.

\section{Gheorghe Florian Borlea și Valentin Dinu}

\section{Abstract. European forests are in danger. we come up with solutions. The 30 th anniversary of PROSILVA}

Pro Silva Europe is an Association of Foresters who advocates forest management based on natural pro- cesses with the aim to ensure the maintenance of European forests vitality, to improve their structure and stability, and to ensure that their varied functions, productivity and profitability are guaranteed in a sustainable way. Its annual 2019 meeting was organised in Radlje ob Dravi, the cradle of close-to-nature forest management located in the North of Slovenia. More than 100 international forestry experts presented their approach into the relation between science and forestry practice by celebrating the 30th anniversary meeting of Pro Silva Europe with the Conference „Forests for the future - from science to the people". The present-day place of forests and forestry in the global and European new challenges context were discussed and the role of Pro Silva Europe was considered in this respect. The first political declaration of Pro Silva Europe was presented by President Eckart Senitza stating that a sustainable development of Pro Silva need an incorporation of private forest owners, state forests, forest administration, scientists in a balanced way. The main discussion focused on the main urgent issues: how is Pro Silva going to contribute to the improvement of the resilience of European forests and which are the main goals of the association for the near future.

Authors. Gheorghe Florian Borlea (fborlea@yahoo. com) - University of Agricultural and Veterinary Sciences of Banat, Timişoara.Romania; Valentin Dinu - Forest District Vlăsia, Târgovişte, Romania. 